\title{
MEASURING PERFORMANCE OF UNIVERSITIES IN FRAGILE COUNTRIES USING ANALYTIC HIERARCHY PROCESS
}

\begin{abstract}
Performance measurement is a process of comparing what transpired with what was planned. Performance measurement assists users to know where they are making progress, where they are slowing down and where they are moving. Due to increasing global competition, both public and private institutions regularly measure their performance levels based on organisational vision and mission. While there are established models to measure performance of universities in developed and developing countries, no such model exist for the universities belonging to fragile countries. This article aims at developing a model based upon AHP to measure performance of universities in fragile countries.
\end{abstract}

Keywords: performance measurement of universities, fragile countries, AHP

\section{Introduction}

There is evidence to support that education environment has changed and universities are facing pressure to measure their performance. Paley et al. (2015) argue that universities are legally responsible for measuring their performance. Common performance weaknesses are being reported in universities, and this has become a quality obstacle to both universities and the countries at large. Srimai et al. (2011) state that in the beginning performance measurement was developed as operations-oriented, and it became a strategic tool for institutions in the late 1980s. Sukboonyasatit et al. (2011) state that no matter how performance assessments may differ from one university to another, academic institutions should pay more attention to improve their performance. Currently, fragile countries' higher education is gradually growing. However, developed countries' performance measurement criteria are not fully applicable to measure the performance of fragile countries' universities.

Fragile countries have witnessed decades of violence and instability. Economically fragile countries are the poorest in the world and their public services such as education and health receive support from international donors. Fragility has many different definitions, and the most widely-accepted definitions are: The capacity and/or willingness of state structures in delivering key services needed for poverty reduction, development, security and the protection of human rights (FASID, 2009). Governments are unable to provide basic services to their citizens. Carment and Samy(2012) highlight that within fragile states, 30 percent are absolutely poor and over 40 percent of the children do not receive primary education. 


\section{Literature Review}

Universities influence human life. There are different stakeholders such as students, parents, employers, and the government, and all of them have different perceptions on the performance of higher education (Arjomandi et al., 2009). The meaning of university extends beyond simply preparing the workforce for the business environment (Bolton \& Nie, 2010). Developing and maintaining better performance in universities can result in the improvement of public and private sectors (Bloom et al., 2006). When university graduates perform better in the working environment, the higher education is considered to have better performance (Yek et al., 2007). To get a higher ranking, universities need to improve the performance of their institutions (Huang, 2011).

Universities are under pressure to provide quality education and to improve performance (Farid et al., 2008). University graduates should be able to address the challenges and the constraints in the society and the environment in which they live (Smulowitz, 2015). Young people need to have higher education because many jobs are available, and the minimum requirement is to have a degree. Wedgwood (2008) and Arjomandi et al. (2009) show that university programmes are designed to fit the market workforce not to solve the challenges and the constraints in the society.

Many researchers have carried out empirical and theoretical studies on performance measurement of higher education. Abdullah and Abdul Rahman (2011) have made an observation on the performance level of Malaysia's higher education. They found that there is a need for strong implementation coordination between the Ministry and higher education institutions. Broady-Preston and Lobo (2011) empirically examined the role and relevance of external standards in demonstrating the value and impact of academic library services to their stakeholders. The finding of the study indicates that an active engagement and partnership with customers is imperative if academic libraries are to be viewed as vital to their parent organisations and thus survive.

Chen et al.(2009) investigated universities' performance measure indicators (PMIs). Data were collected from different sources such as US News, World Report, UK University Committee Reports, 13 scholars invited to participate and opinions from the Ministry of Education. The findings indicate that university should use self-evaluation performance indicator to achieve the objective of performance management. Chu and $\mathrm{Li}$ (2000) surveyed 84 key Chinese higher education Institutions and measured the research performance. It is found that research performance in different regions in China has improved, however, in general authors have reported that institutions suffer inefficiency on technical matters.

Mohd and Borhandden (2012) proposed to examine the relationship between the quality culture and workforce performance in the Malaysian higher education sector. Samplewise the author employed a total of 267 academic staff from the International Islamic University Malaysia. Finally, study findings reported that there exists statistically significant correlation between quality culture and workforce performance. Mohayidin et 
al. (2007) focused onimplementation of an excellent knowledge management (KM) system for Malaysian Universities. The study conducted eight public and local private universities. Srimai et al. (2011) studied nature and force of the transitionary paths of performance. The study stated that measuring performance evolves four major paths from operations to strategic, measurement to management, static to dynamic and economicprofit to stakeholder focus.

\subsection{AHP in Higher Education}

AHP is applied in different areas of higher education, such as measuring quality, faculty evaluation, measuring performance, strategic planning, and university selection. In recent years, measuring quality is one of the most common issues addressed in higher education. Lam and Zhao (1998) apply AHP to evaluate seven teaching tools for achieving ten educational objectives. Islam (2007) employs AHP to assign weights MBNQA Criteria in Education: from a Malaysian perspective and proposition of an alternative evaluation scheme. Yayla and Ortaburun (2011) use AHP to measure the relationship on the feedback provided by academics and employers on the undergraduate curriculum for teaching design in Turkey.

Evaluating faculty plays a vital role and it helps in hiring lecturers as well as promoting universities. Bahurmoz (2003) applied AHP to identify the best potential lecturers in a private women's college in Jeddah. Badri and Abdulla (2004) conduct a study by evaluating process of faculty members' performance. Several researches applied AHP in measuring performance. Ho et al.(2006) apply AHP to measure the performance of lecturers and students of an institution in UK. Hsieh et al. (2006) used AHP to assess the performance of e-library system. Hayrapetyan and Kuruvila (2011) studied how Decisions Support System allows the dean of a college to calculate relative contributions of each faculty member towards the success of the college based on their institutional mission and goals. The study employed AHP and the finding indicates that the evaluation process is robust and scientifically justified. Salmuni and Mohd (2005) aimed to develop a model for promoting academic staff. AHP technique is utilised to identify and prioritise the criteria for promoting academic staff. The finding showed that the most important component with the highest weight is teaching (0.3029).

Different AHP studies were conducted to address issues and challenges in the selection of university. Soltani and Talebi (2010) used AHP to rank eight major specialisations offered by universities in Iran selection criteria were based on Iran's education and industry requirements. Tas and Akagun(2012) conducted a study applying AHP to select a university in the United States. Jayakumar et al.(2010) applied AHP to select engineering colleges in India.

\subsection{Criteria Weights of MBNQA Variables}

The MBNQA self-assessment model has a total score of 1,000 points. Each category is scored based on the approach used to address the category, how well it is deployed 
throughout the organisation. Organisations that apply for the Baldrige Award are judged by an independent board of examiners.

Leadership: This category in MBNQA framework carries 120 points on leadership. It is the second highest score after the result category. MBNQA examiners identify areas such as university governance system, leaders' commitment to university sustainability and they also examine how leaders give priority to the social responsibility and legal ethics of the community. Senior leaders are the heads of the university, who are obligated to guide the university to achieve high quality performance through the university's vision, mission, and values, by promoting legal and ethical behaviour, and creating a sustainable organisation. Hence, MBNQA examiners evaluate how senior leaders develop and deploy the university's vision, mission and core values.

Strategic Planning: Strategic planning is the second criterion of MBNQA framework and it carries 85 points. MBNQA examiners measure the different areas within the university's strategic plan, this includes having a proper strategic plan, implementing strategic objectives with an action plan and measuring the method of progress. In the case of the strategic development process which refers to a university's approach for future planning, universities are required to explain in detail the method used to develop the strategic planning, the core participants who developed the strategy and the decisionmaking process. Additionally, respondents should show the link between organisation's profile (vision and mission) and strategy. Examiners of MBNQA evaluate how the organisation develops strategic objectives and action plans, not only that they also examine how it is implemented and how the progress is measured.

Customer and Market Focus: Drawing from Shutler and Crawford (1998), university customers are mainly students. Generally, listening to the voice of customers (students and stakeholders) can help the university to get more information from them. MBNQA examiners evaluate the relationship with the customers and the method of getting more feedback from them in order to improve quality in performance. Examination of this variable involves considering how the organisation listens to the voice of its customers (students and stakeholders), builds customer relationships and uses customer information to improve and identify opportunities for innovation. The MBNQA judges would prefer to know the dissatisfactions of students and stakeholders. The carry mark for this category is 85 points.

Measurement, Analysis, and Knowledge Management: The carry mark of this category is 90 points. The organisation is required to describe how it measures, analyses, reviews and improves its performance through the use of data and information at all levels and in all parts of the organisation. The examiners also evaluate how the organisation applies information technology.

Workforce Focus: Like strategic planning this category also carries 85 points. The examiners of MBNQA assess how conducive the environment is (organisation maintains a safe, secure and supportive work climate), how the organisation engages, manages and develops the workforce to utilise its full potential in alignment with the overall mission, strategy and action plans of the organisation. 
Operation Focus: Examiners evaluate how the institution designs, manages and improves its work systems and work processes. Moreover, the judges will observe how the institution prepares to protect potential emergencies. The carry mark for this category is 85 points.

Organisational Performance Results: This category carries the highest point which is 450. The examiners evaluate the key areas of the institution such as student learning and process outcomes, customer-focused outcomes, workforce-focused outcomes, leadership and governance outcomes, and budgetary, financial and market outcomes. All performance levels are examined. Figure 3.7 depicts the MBNQA model.

\section{METHODOLOGY}

The primary objective of this study is to assign weights criteria for measuring performance universities in fragile countries using Analytic hierarchy process (AHP). AHP was introduced by Thomas L. Saaty in the 1970s. AHP applications are growing fast and a wide variety of researches on AHP are available. AHP publications appear in academic journals and it has been used in various fields, including education, health, politics, sports, military and transportation. AHP method has been validated in many applications (Goyal et al., 2015)

\subsection{The Analytic Hierarchy Process (AHP)}

AHP helps decision makers to address real life problems. AHP does not need advanced technical knowledge and it takes into human judgements based on people's feelings and emotions. AHP deals with both tangible and intangible factors and presents the problem in a hierarchic structure. Decision-making with AHP is based on ranking factors in terms of their relative importance.

AHP is a powerful decision-making tool; it is used to prioritise alternatives represent to the criteria in terms of their importance. AHP allows a mixture of data both qualitative and quantitative. Islam (2007) indicates that AHP considers both subjective and objective factors in the decision-making process. Application of AHP instrument helps to design, analyse, test and validate the performance measurement model. Below are the basic AHP steps:

- State the overall objective of the problem and identify the criteria and subcriteria

- Structure the problem as a hierarchy of criteria, sub-criteria, and alternatives

- Obtain pairwise comparisons of all elements in the hierarchy

- Obtain the priority vector, normalising the vector in each column of a pairwise comparison matrix

- Compute the consistency ratio of the matrix

- Synthesise the local priorities over the hierarchy to obtain an overall for each alternative 


\subsection{Relative Measurement}

In the relative measurement, elements were compared with each other to derive priorities. The process assumes the criteria set dependent on each other in a measurement. This indicates that relative measurement only deals with dependence. The first step is to compare the elements in each level in pairs. The comparisons were made using judgement based on knowledge and experience. When making a comparison as a unit of an estimate, one may choose the smaller or larger intensity factor. Saaty (2006) points out that relative measurement is the only meaningful approach for most decision problems that do not have precedence.

In the relative measurement two questions were asked which are dominance and intensity. The dominance asks which of the two elements has priority or meets the criteria more, while intensity identifies how much more? All the pairwise comparisons are completed using a scale. The final step is a weighting process that uses these priorities and synthesises the overall importance preference of the criteria, sub-criteria, and alternatives.

\subsection{Data collection}

Data were collected by using pairwise comparison. To understand the process, the researcher first explained the pairwise comparison method to the respondents and there was also one example in the questionnaire about how PCM works. The respondents were then asked to follow a guideline.

\subsection{Pairwise Comparison Matrix (PCM)}

AHP derives ratio scales of the relative magnitude of a set of elements by making paired comparisons. After respondents prioritised criteria to be included in the model, the next step was to determine the pairwise comparison matrix of the criteria. Even though each factor is important, they are not equally important. Using ratio scale judgement $(1 / 9,9)$ weights were assigned to each criterion based on its importance. Table 1 indicates ratio scale judgement (Saaty, 1990).

Table 1: Saaty's Ratio Scale Judgement

\begin{tabular}{lc}
\hline Verbal judgement of importance & Numerical rating \\
\hline Equal importance & 1 \\
Equal to moderate importance & 2 \\
Moderate importance & 3 \\
Moderate to strong importance & 4 \\
Strong importance & 5 \\
Strong to very strong importance & 6 \\
Very strong importance & 7 \\
Very strong to extremely strong importance & 8 \\
Extreme importance & 9 \\
\hline
\end{tabular}

The researcher asked decision makers to use their judgements to compare the elements' relative importance by using a pairwise comparison. Fifty-five (55) respondents were targeted Table 2 indicates respondents' demographic information.

International Symposium on
Hong Kong, HK July 13 - July 15, 2018 
ISAHP Article: Islam and Mohamed/Measuring Performance of Universities in Fragile Countries

Using Analytic Hierarchy Process

Table 2 : Respondents' Demographic Information

\begin{tabular}{|c|c|c|}
\hline Variable* & Frequency & Percentage \\
\hline \multicolumn{3}{|l|}{ Gender } \\
\hline - Male & 45 & 81.81 \\
\hline - Female & 10 & 18.18 \\
\hline \multicolumn{3}{|l|}{ Country } \\
\hline - Somalia & 25 & 45.45 \\
\hline - Afghanistan & 10 & 18.18 \\
\hline - Chad & 7 & 10.90 \\
\hline - $\quad$ Sudan & 13 & 25.45 \\
\hline \multicolumn{3}{|l|}{ Age group } \\
\hline - 31-40 years & 13 & 23.63 \\
\hline - $41-50$ years & 32 & 58.18 \\
\hline - 51- years and above & 10 & 18.18 \\
\hline \multicolumn{3}{|l|}{ Highest level of education } \\
\hline - Diploma & 0 & 00.00 \\
\hline - Professional & 0 & 00.00 \\
\hline - Bachelors & 8 & 14.55 \\
\hline - $\quad$ Masters & 29 & 52.72 \\
\hline - PhD. & 18 & 32.72 \\
\hline \multicolumn{3}{|c|}{ No. of years the institution exists } \\
\hline - less than 5 years & 0 & 0.00 \\
\hline - 5-10 years & 4 & 21.05 \\
\hline - $10-20$ years & 7 & 36.84 \\
\hline - more than 20 years & 8 & 42.10 \\
\hline \multicolumn{3}{|c|}{ No. of years the institution served } \\
\hline - less than 3 years & 0 & 0 \\
\hline - 3-5 years & 9 & 16.36 \\
\hline - 5-10 years & 27 & 49.09 \\
\hline - more than 10 years & 19 & 34.54 \\
\hline \multicolumn{3}{|l|}{ Position in the institution } \\
\hline - Lecturer & 35 & 63.63 \\
\hline - $\quad$ Admin & 20 & 36.36 \\
\hline
\end{tabular}

\subsection{Criteria Weights}

This section focuses on determining the weights of the criteria and sub-criteria. Different methods are used to extract weights from pairwise comparison matrices. This study employed eigenvector method used in Super Decisions Software. Data for pairwise comparisons were collected from the respondents. The eigenvector method determines 
the priority weights of the factors in pairwise comparison matrices. A pairwise comparison matrix looks like the following.

$$
\mathrm{A}=\left(\begin{array}{cccc}
\frac{w_{1}}{w_{1}} & \frac{w_{1}}{w_{2}} & \Lambda & \frac{w_{1}}{w_{n}} \\
\frac{w_{2}}{w_{1}} & \frac{w_{2}}{w_{2}} & \Lambda & \frac{w_{2}}{w_{n}} \\
\mathrm{M} & \mathrm{M} & & \mathrm{M} \\
\frac{w_{n}}{w_{1}} & \frac{w_{n}}{w_{2}} & \Lambda & \frac{w_{n}}{w_{n}}
\end{array}\right)
$$

Where, $\mathrm{w}_{1}, \mathrm{w}_{2} \ldots, \mathrm{w}_{\mathrm{n}}$ are the numerical weights of the criteria. Multiplying $\mathbf{A}$ by W will get the below equation

$$
\left(\begin{array}{cccc}
\frac{w_{1}}{w_{1}} & \frac{w_{1}}{w_{2}} & \Lambda & \frac{w_{1}}{w_{n}} \\
\frac{w_{2}}{w_{1}} & \frac{w_{2}}{w_{2}} & \Lambda & \frac{w_{2}}{w_{n}} \\
\mathrm{M} & \mathrm{M} & & \mathrm{M} \\
\frac{w_{n}}{w_{1}} & \frac{w_{n}}{w_{2}} & \Lambda & \frac{w_{n}}{w_{n}}
\end{array}\right)_{n \times n}\left(\begin{array}{l}
w_{1} \\
w_{2} \\
\mathrm{M} \\
w_{n}
\end{array}\right)_{n \times 1}
$$

$\mathrm{AW}=\mathrm{nW}$

A positive $n$ by $n$ matrix has the ratio form $A=(w 1 / w j), i, j=1, \ldots ., n$, and only if, it is consistent. For an inconsistent matrix, eigenvalue equation will be the following:

$$
A^{\prime} w^{\prime}=\lambda_{\max } w^{\prime}
$$

In this case, it is necessary to determine the highest eigenvalue of $\mathbf{A}$ Meanwhile; "wi" will be determined by employing the equations of linear simultaneous.

$$
w_{i}=\frac{1}{\lambda_{\max }} \sum_{j=1}^{n} a_{i j} w_{j}, \quad i=1,2, \ldots, n
$$

To normalise the weights, the following equation will be employed:

$$
\sum_{i=1}^{n} w_{i}=1
$$




\subsection{Measuring Consistency}

Consistency is about ensuring whether the respondents are consistent with all the judgements. AHP provides a process for checking the inconsistency for a pairwise comparison matrix. Inconsistency is a natural human trait to allow for changing minds when new facts come to light. Therefore, the AHP allows a certain level of overall inconsistency. If CR value exceeds $0.10, \mathrm{PCM}$ needs to be revised. "higher ratios indicate lower consistencies" if it is less than 0.10 , then it is acceptable.

In the process, the researcher computes consistency index (CI) and the formula is

as follows:

$$
C I=\frac{\lambda_{\text {nx }}-n}{n-1}
$$

Where $\lambda_{\max }$ is the largest eigenvalue of the pairwise comparison matrix. To determine the actual consistency, the following formula is usually used:

$$
\text { Consistency Ratio }=\frac{\text { Consistency Index }}{\text { Random Index }}
$$

The value of Random Index depends on the size of pairwise comparison matrix. Table 3 indicates the Random Index (RI).

\begin{tabular}{|c|c|c|c|c|c|c|c|c|c|c|}
\hline No & 1 & 2 & 3 & 4 & 5 & 6 & 7 & 8 & 9 & 10 \\
\hline RI & 0 & 0 & 0.52 & 0.89 & 1.11 & 1.25 & 1.32 & 1.40 & 1.45 & 1.49 \\
\hline
\end{tabular}

Table 3: Random Index (RI)

\section{Data Collection and Analysis of Results}

The AHP is a widely used method for model development. This section details the steps applied to implement the AHP method in this study. During the data collection, all essential criteria and sub-criteria relevant to the performance measurement were indicated on the second page of the questionnaire. This informed respondents about the categories before they started prioritising. Respondents were asked to compare categories regarding their importance to the goal to get weights from a Pairwise Comparison Matrix (PCM).

The researcher contacted 100 target respondents from four Somalia, Sudan, Afghanistan, and Chad. Out of the 100, 55 respondents provided feedback on AHP pairwise comparison whereas others were not available due to varied reasons. The study employed verbal judgement decision-making method which is a fundamental pillar in the AHP. During data collection, respondents were explained the $(1 / 9,9)$ ratio scale used in completing the pairwise comparison matrix.

Figure 1 shows a complete set of PCMs received from the 55 respondents where acronyms have been used for the PCM, while the full forms of the criteria and sub- 
ISAHP Article: Islam and Mohamed/Measuring Performance of Universities in Fragile Countries Using Analytic Hierarchy Process

criteria have been provided in Table 4.The geometric mean method has been applied to combine the judgements for the criteria and sub-criteria for all respondents. Islam (2007) argues that rather than determining individual matrices each time, the geometric mean is best suited to determine the weights of the criteria and sub-criteria for all respondents at one time. In this regard, matrices of criteria and sub-criteria from all respondents were aggregated using geometric means. Table 4 indicates the overall weights of the criteria and the sub-criteria derived from all respondents.

Table 4: Overall Weights of the Criteria and the Sub-criteria derived from all Respondents

\begin{tabular}{|c|c|c|}
\hline Criteria & Criteria Weights & Sub-criteria Weights \\
\hline Leadership (L) & 214 & \\
\hline Senior Leadership (SL) & & 128 \\
\hline Corporate Social Responsibility (CSR) & & 86 \\
\hline Strategic Planning (SP) & 110 & \\
\hline Strategic Development ( $S D$ ) & & 52 \\
\hline Strategic Implementation (SI) & & 58 \\
\hline Work Processes (WP) & 104 & \\
\hline Administrative Work Process (ADWP) & & 37 \\
\hline Academic Work Process (ACWP) & & 67 \\
\hline Faculty and Staff Recruitment (FSR) & 109 & \\
\hline Academic Qualification $(A Q)$ & & 45 \\
\hline Working Experience (WE) & & 33 \\
\hline Staff Recruitment Process (SRP) & & 31 \\
\hline Student Focus (SF) & 98 & \\
\hline Student Satisfaction (SS) & & 51 \\
\hline Student Dropouts (SD) & & 25 \\
\hline Teacher-Student Ratios (TSR) & & 22 \\
\hline Campus Facility (CF) & 120 & \\
\hline Infrastructure (I) & & 52 \\
\hline Learning Materials (LM) & & 45 \\
\hline Hostel $(H)$ & & 23 \\
\hline Technology (T) & 81 & \\
\hline Internet (IN) & & 48 \\
\hline Digital Library $(D L)$ & & 33 \\
\hline Curriculum (C) & 80 & \\
\hline Standard Curriculum (SC) & & 46 \\
\hline Original Textbooks (OTB) & & 34 \\
\hline Results (R) & 84 & \\
\hline Academic Performance Result (APR) & & 25 \\
\hline Student Employability Result (SER) & & 11 \\
\hline Research and Publication Result (RPR) & & 8 \\
\hline Faculty and Staff Wellbeing Result (FSWR) & & 16 \\
\hline Student Satisfaction Result (SSR) & & 24 \\
\hline Total & 1000 & 1000 \\
\hline
\end{tabular}


ISAHP Article: Islam and Mohamed/Measuring Performance of Universities in Fragile Countries Using Analytic Hierarchy Process

The sets of PCM for all respondents were calculated and Super Decisions Software was used to receive overall weights for all respondents. Figure 1 contains the synthesised matrices and the weights derived from each PCM.

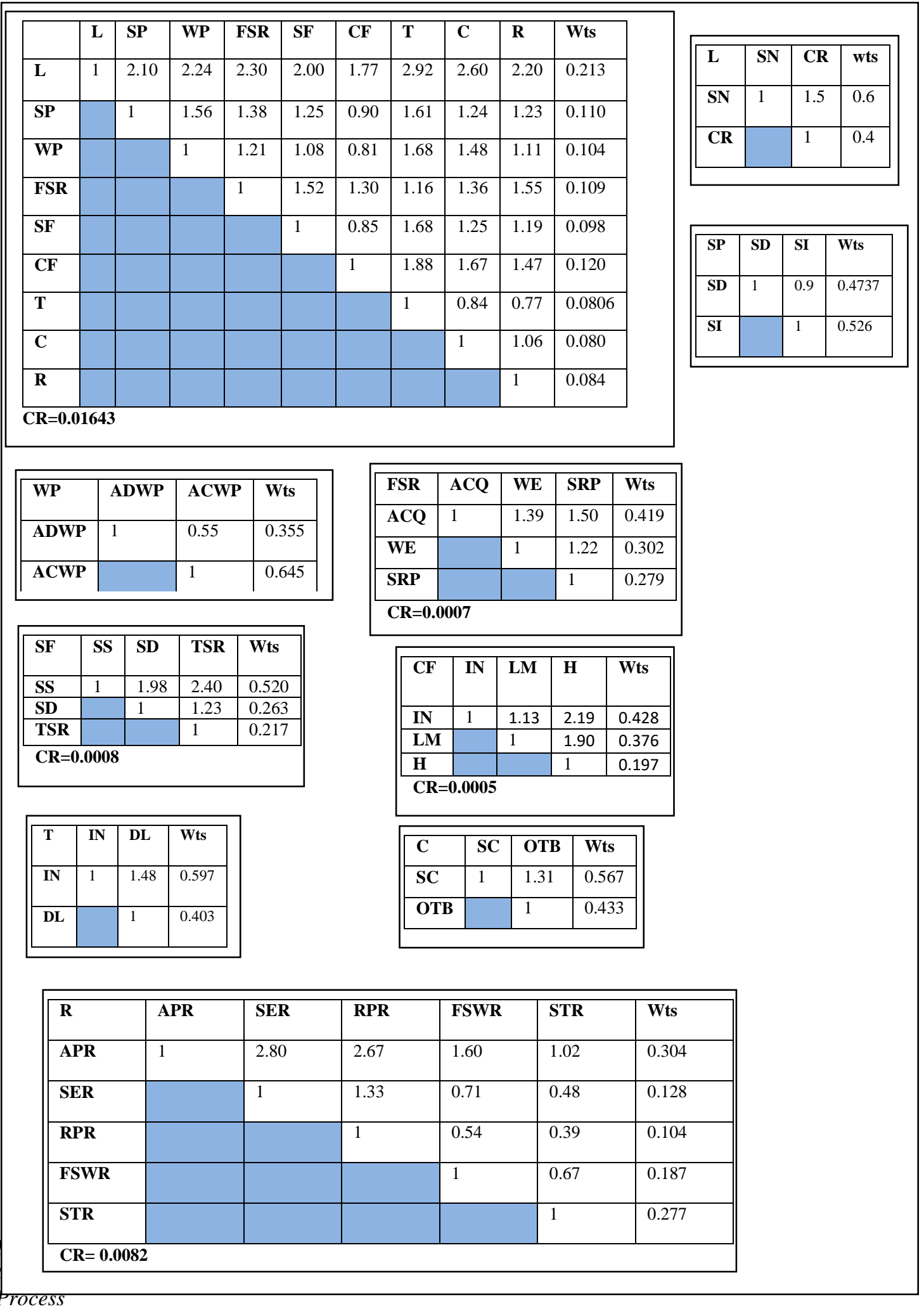


Figure 1: Overall average pairwise comparison matrices derived from all respondents.

\subsection{Some Observations in the New Set of Overall Weights}

Leadership: Respondents believe that having good leadership can improve performance. The leadership category obtained significantly higher weights than other categories. The category received 214 points which make it the highest category. For the sub-criteria category, respondents emphasised the positive impact of senior leadership which received a high significance of 128 points. The result also shows that respondents assigned lesser weights to CSR with only 86 points.

Strategic Planning: Unlike leadership, respondents assigned lesser weights to strategic planning. The category received 110 points. For the sub-criteria categories, strategic implementation received slightly higher weight than strategic development with 58 and 52 , respectively.

Work Processes: The overall weight that the category received was 104 points, which make it an average category. With regard to the sub-categories, administrative work process and academic work process, respondents assigned significantly higher weight to academic work process than administrative work process with 67 and 37 respectively.

Faculty and Staff Recruitment: Faculty and staff recruitment received a total weightage of 109 points which makes it an average priority. In the case of the sub-criteria, respondents assigned higher weightage to academic qualification than working experience and staff recruitment with 45,33 , and 31 respectively.

Student Focus: The analysis shows that due to other categories being assigned higher weights, this category received only 98 points. The category contains three sub-criteria comprising student satisfaction, student dropouts, and teacher-student ratio. Respondents prioritised student satisfaction higher than student dropouts and teacher-student ratio with 51,25 , and 22 respectively.

Campus Facility: The category received 120 points which make it the second highest category after leadership. With regard to the sub-criteria, respondents assigned higher significance to infrastructure with 52 points, followed by learning materials with 46 . Hostel received the least priority with 23 points.

Technology: Technology plays an important role in the performance of universities in fragile countries. However, it received less weightage compared to other categories with 81points.The category has two sub-criteria namely internet and digital library. The internet received a higher weight with 48 compared with digital library with 33 points.

Curriculum: One reason that some categories receive lesser weights is that other categories receive higher weights and it is not possible in PCM to attribute a high weight to all categories. With this, respondents assigned curriculum weightage of 80 points. 
ISAHP Article: Islam and Mohamed/Measuring Performance of Universities in Fragile Countries Using Analytic Hierarchy Process

With regard to the sub-category, respondents prioritised standard curriculum with 46 points while original textbooks scored 34 points.

Results: This category is an important factor for universities and is supposed to be assigned a higher weightage, however, due to the many challenges facing universities, the category received a weightage of only 84 points. With regard to sub-categories, academic performance result received the highest weight with 25 followed by student satisfaction result 24, faculty and staff wellbeing result was assigned 16 points, while student employability result was assigned 11 points. Respondents showed the least interest in research and publication result with only eight points.

\section{Conclusion}

Performance measurement of universities is vital. The evaluation results show the position of the universities - to what extent the objectives and targets have been achieved. Considerable amount of research works have been done to develop evaluation model to measure performance of universities in developed and developing countries. However, the works to measure performance of universities in fragile countries is limited. This research fills up this gap by developing a comprehensive model to performance of universities in fragile countries.

\section{Reference}

Abdullah, N. A., \& Rahman, S. A. (2011). Making strategy at a Malaysian higher education Institution. International Proceedings of Economics Development \& Research, 22(2), 193-197

Arjomandi, M., Kestell, C., \& Grimshaw, P. (2009). An EFQM Excellence Model for Higher Education Quality Assessment. In 20th Annual Conference for the Australasian Association for Engineering Education, 6-9 December 2009: Engineering the Curriculum (p. 1015). Engineers Australia.

Bailey, B. D. (2015). The Malcolm Baldrige National Quality Award Process in Public Higher Education Institutions and Effects on Organizational Performance: A Historical Perspective.

Badri, M. A., \& Abdulla, M. H. (2004). Awards of Excellence in Institutions of Higher Education: an AHP Approach. International Journal of Educational Management, 18(4), 224-242.

Bahurmoz, A. M. (2003). The analytic hierarchy process at Dar al-Hekma, Saudi Arabia. Interfaces, 33(4), 70-78.

Bloom, D. E., Canning, D., \& Chan, K. (2006). Higher education and Economic Development in Africa (Vol. 102). Washington, DC: World Bank. 
ISAHP Article: Islam and Mohamed/Measuring Performance of Universities in Fragile Countries Using Analytic Hierarchy Process

Bolton, D., \& Nie, R. U. I. (2010). Creating Value in Transnational Higher education: The Role of Stakeholder Management. Academy of Management Learning \& Education, 9(4), 701-714.

Broady-Preston, J., \& Lobo, A. (2011). Measuring the Quality, Value and Impact of Academic Libraries: The Role of External Standards. Performance Measurement and Metrics, 12(2), 122-135.

Carment, D.,\&Samy, Y. (2012). Assessing State Fragility: A country Indicator for Foreign

Policy Report.Retrieved from Cifp Website.http://www4.carleton.ca/cifp/

Chen, S. H., Wang, H. H., \& Yang, K. J. (2009). Establishment and Application of Performance Measure Indicators for Universities. The TQM Journal, 21(3), 220-235.

Chu Ng, Y., \& Li, S. K. (2000). Measuring the Research Performance of Chinese Higher Education Institutions: An Application of Data Envelopment Analysis. Education Economics, 8(2), 139-156.

Farid, D., Nejati, M., \& Mirfakhredini, H. (2008). Balanced Scorecard Application in Universities and Higher Education Institutes: Implementation Guide in an Iranian Context. Universitatii Bucuresti. Analele. Seria Stiinte Economice si Administrative, 2(3), $29-40$.

FASID. (2009).Study Report on Development Strategy of Fragile States.Globalization and International Development Research.

Goyal, P., Rahman, Z., \& Kazi, A. A. (2015).Identification and Prioritization of Corporate Sustainability Practices Using Analytical Hierarchy Process. Journal of Modelling in Management, 10(1), 23 - 49.

Ho, W., Dey, P. K., \&Higson, H.E. (2006). Multiple Criteria Decision-Making Techniques in Higher Eeducation. International Journal of Educational Managemen, 20(5), 319-337.

Hayrapetyand, L. R.,\& Kuruvila, M. (2011). An AHP-based decision support system for faculty Evaluation.International Journal of Business, Marketing and Decision Sciences, 4(1), 68-79.

Huang, H. M. (2011). A Comparison of Three Major Academic Rankings for World Universities: From a Research Evaluation Perspective.Journal of Library and Information Studies,9(1), 1-25.

Hsieh, L. F., Chin, J. B., \& Wu, M. C. (2006). Performance Evaluation for University Electronic Libraries in Taiwan. The Electronic Library, 24(2), 212-224.

Islam, R. (2007). MBNQA Criteria in Education: Assigning Weights from a Malaysian Perspective and Proposition of an Alternative Evaluation Scheme. International Transactions in Operational Research, 14(5), 373-394.

International Symposium on $\quad 14$

Hong Kong, HK the Analytic Hierarchy July 13 - July 15,2018

Process 
ISAHP Article: Islam and Mohamed/Measuring Performance of Universities in Fragile Countries Using Analytic Hierarchy Process

Jayakumar, V., Raju, R., Mariappan, C.,\& Ravivikram, I. (2010). An Analytic Hierarchical Approach to Decision Making for Selection of Engineering Colleges in Tami Nadu.IUP Journal of Operations Management, 9(3),16-28.

Mohd Ali, H., \& Borhandden Musah, M. (2012).Investigation of Malaysian Higher Education Quality Culture and Workforce Performance.Quality Assurance in Education, 20 (3), $289-309$.

Mohayidin, M. G., Azirawani, N., Kamaruddin, M. N., \& Margono, M. I. (2007). The Application of Knowledge Management in Enhancing the Performance of Malaysian Universities. The Electronic Journal of Knowledge Management, 5(3), 301-312.

Lam, K., \&Zhao., X. (1998). An application of Quality Function Deployment to ImproveThe Quality of Teaching. International Journal of Quality \& Reliability Management, 15 (4), $389-413$.

Paley, J., Cottrill, J., Errecart, K., White, A., Schaden, C., Schrag, T., Douglas, R., Tahmassebi, B., Crocker, R., \& Streatfield, D. (2015). The evolution of Global LibrariesPerformance Measurement and Impact Assessment Systems, Performance Measurement and Metrics, 16 (2), 132 - 158.

Salmuni, W., \&Mohd, S. (2005). The Analytical Hierarchy Process: Multi Criteria Decision Making for Promoting Academic Staff in Higher Education.European Journal of Operation. 9(3), 5-20.

Saaty, T. L. (2006). Rank From Comparisons and From Ratings in the Analytic Hierarchy/network Processes. European Journal of Operational Research,168(2), 557570.

Smulowitz, S.(2015).Evidence for the Performance Prism in Higher Education.Measuring Business Excellence, 19(1), 70 - 80

Soltani, M., \& Talebi, D. (2010). Clustering and Ranking University Majors Using Data Mining and AHP Algorithms: A Case study in Iran Abbas Rad Abolfazl Kazzazi. Iranian Journal of Management Sciences, 5(17), 113.

Shutler, P. M., \&Crawford, L.(1998). The challenge of ISO 9000 Certification in Higher Education. Quality Assurance in Education. 6(3), 152 - 161.

Srimai, S., Radford, J., \&Wright, C. (2011). Evolutionary Paths of Performance Measurement: An overview of its Recent Development. International Journal of Productivity and Performance Management, 60(7), 662 -687.

Sukboonyasatit, K., Thanapaisan, C., \&Manmar, L. (2011). Key Performance Indicators of Public Universities Based on Quality Assessment Criteria in Thailand. Contemporary Issues in Education Research.ProQuest Education Journals,4(9), 9-18. 
ISAHP Article: Islam and Mohamed/Measuring Performance of Universities in Fragile Countries Using Analytic Hierarchy Process

Tas, A., \&Akagun, E. A. (2012). Key Factors for Student Recruitment: The Issue of University Branding. International Business Research. 5(10), 146-152.

Wedgwood, M. (2008). Higher education for the Workforce: Barriers and Facilitators to Employer Engagement. Manchester Metropolitan University.

Yayla, Y., \&Ortaburun, Y. (2011). Redesigning Curriculum in Higher Education by Using Analytical Hierarchy Process and Spearman Rank Correlation Test. European Journal of Scientific Research,52 (2),271-279.

Yek, T. M., Penney, D., \& Seow, A. (2007). Using Balanced Scorecard (BSC) to Improve Quality and Performance of Vocational Education and Training (VET): A Case Study in Singapore. In AARE 2007 Conference (pp. 1-25). 